() А. П. Гавриш, д.т.н., професор, Т. А. Роїк, д.т.н., професор, П. О. Киричок, д.т.н., професор, О. І. Лотоцька, к.т.н., доцент, НТУУ «КПІ», Київ, Україна

\title{
СИЛОВЕ ПОЛЕ ПРИ ТОНКОМУ АЛМАЗНОМУ ШЛІФУВАННІ ДЕТАЛЕЙ ТЕРТЯ З НОВИХ КОМПОЗИЦІЙНИХ МАТЕРІАЛІВ НА ОСНОВІ НІКЕЛЮ
}

\section{У статті наведено результати дослідження впливу} на складові сил різання при тонкому алмазному шліфуванні деталей тертя 3 нових композиційних матеріалів, створених на базі відходів виробництва деталей з нікелевих сплавів типу ХН55ВМТКЮ, ХН50ВТФКЮ, ЭП975 у електротехнічній, радіоелектронній та аерокосмічній галузях промисловості України, синтезованих для важких умов роботи поліграфічної техніки. Встановлено закономірності впливу режимних факторів шліфування, типу алмазу, зернистості та матеріалу зв'язки алмазного кругу на параметри якості поверхонь оброблення з урахуванням механізму формування складових сил різання на різальній крайці алмазного зерна у зоні різання матеріалу. Визначено залежності шорсткості поверхонь оброблення нових високошвидкісних композитних сплавів від режимів процесу алмазного шліфування (швидкості обертання, поздовжньої подачі, швидкості обертання алмазного кругу та зернистості алмазних зерен в інструменті). Розроблено рекомендації з вибору алмазних кругів та режимів різання для промисловості, які забезпечують якість поверхонь тертя високошвидкісних підшипників ковзання для друкарської техніки.

Ключові слова: нові композитні матеріали; сили різання; шліфувальні круги з алмазу; зернистість; тип зв'язки; алмазне шліфування; режими різання.

\section{Постановка проблеми}

Вимоги до деталей тертя, які працюють в умовах інтенсивного зношування, постійно зростають. Це обумовлює необхідність створення та вдосконалення існуючих технологій виготовлення деталей такого типу, включно із синтезом нових видів матеріалів та розробкою фінішних операцій технологічного процесу надтонкої алмазної обробки робочих поверхонь тертя з забезпеченням відповідно до високих вимог до якості оброблення (мінімальних значень параметрів шорсткості поверхонь $\mathrm{R}_{\mathrm{a}}$, мінімальних спотворень,

(C) $2016 \mathrm{p}$. 
знаку та значень залишкових напружень, дефектів тонкого поверхневого шару, глибини залягання наклепу, ступеня деформації металу в зоні зрізання стружки поодиноким абразивним зерном). Ці якості формують умови придатності поверхні оброблення задля задоволення високих функціональних вимог експлуатації, зокрема суттєвого підвищення термінів служби машин та механізмів друкарської техніки [1-8].

На жаль, усі ці питання недостатньо досліджено, оскільки нові композиційні матеріали (на основі цінних шліфувальних відходів інструментальних сталей) для деталей, які працюють у жорстких умовах експлуатації, лише нещодавно були створені і почали застосовуватись у промисловості [9-15].

Відомо, що на параметри зносостійкості поверхонь тертя суттєво впливають не тільки параметри шорсткості $\mathrm{R}_{\mathrm{a}}, \mathrm{a} \breve{\text {, }}$ що не менш важливо, фізичні властивості тонкого шару поверхонь оброблення. Ці властивості (відповідно до загальної теорії шліфування) забезпечуються при обробці взаємодією силового та температурного полів на різальному лезі алмазного зерна шліфувального інструменту [16-27].

Таким чином, дослідження параметрів силового поля (складових сил різання) при тонкому алмазному шліфуванні нових композиційних матеріалів на основі цінної вторинної сировини високолегованих, високозносостійких сплавів на основі нікелю ХН55ВМТКЮ, ХН50ВТФКЮ, ЭП975 тощо $€$ актуальним питанням, що має наукове та практичне значення.

\section{Мета роботи}

Метою цієї роботи було дослідження складових сил різання $\mathrm{P}_{\mathrm{x}}, \mathrm{P}_{\mathrm{y}}, \mathrm{P}_{\mathrm{z}}$ при алмазній обробці деталей з нових композиційних сплавів на основі відходів нікелевих сплавів ХН55ВМТКЮ, ХН50ВТФКЮ, ЭП975 з домішками твердого мастила, $\mathrm{CaF}_{2}$, а також встановлення впливу зернистості шліфувального кругу, типу зв'язки кругу і режимів різання на параметри силового поля.

Завданнями дослідження було:

1. Виконати низку експериментів, спрямованих на визначення складових сил різання при фінішній механічній обробці зразків з нових композиційних матеріалів на основі шліфувальних відходів.

2. Визначити характер впливу зернистості алмазного шліфувального кругу та типу зв'язки кругу на параметри силового поля.

3. Встановити вплив режимів різання на параметри силового поля при тонкому алмазному шліфуванні досліджуваних матеріалів.

4. Узагальнити отримані результати та зробити висновки.

5. Сформулювати практичні рекомендації для промисловців.

\section{Результати проведених досліджень}

Експериментальне вивчення силового поля, зокрема складових сил різання $\mathrm{P}_{\mathrm{x}}, \mathrm{P}_{\mathrm{y}}, \mathrm{P}_{\mathrm{z}}$ при тонкому алмазному шліфуванні деталей тертя з нових компози- 
ційних сплавів, виконувалось згідно з методикою, наведеною у працях [8, 23-27].

Як вже зазначалося вище, сили різання при шліфуванні металів є джерелом виникнення в зоні різання високих температур та залишкових пластичних деформацій у поверхневих шарах виробу. Сили різання при шліфуванні залежать від міцностних характеристик оброблюваного матеріалу, складу алмазного кругу та режимів шліфування [8, 15-21, 23-25].

Для утворення стружки, різальні крайки алмазних зерен вдавлюються в матеріал деталі, і на оброблюваній поверхні утворюються канавки в напрямку руху кругу.

Згідно з різними дослідженнями процесів мікрорізання та шліфування, встановлено, що при малих глибинах вдавлювання алмазного зерна відбувається пластичне деформування без зрізання стружки - видавлювання матеріалу з боків риски від проходження зерна; лише при глибині вдавлення 0,06-0,1 мкм починається процес утворення стружки перед різальними зернами [15-27].

У зв'язку з тим, що алмазні зерна шліфувального кругу перебувають на значній відстані одне від одного і для металевих матеріалів діаграми розтягу при однакових повторних навантаженнях співпадають 3 діаграмою розвантаження, то пружний стан металу можна розглядати як результат силової дії одиничного зерна.

Зміцнення поверхневого шару $€$ результатом нормальної складової сили різання. Тому ступінь наклепу приблизно може характеризуватися величиною нормальної складової сили різання, що припадає на одиничне зерно.

Враховуючи те, що різальні зерна алмазного кругу перебувають на однаковій відстані $\mathrm{L}_{\phi}$ одне від одного, можна вважати, що кожному зерну відповідає площа $\mathrm{L}_{\phi}{ }^{2}$.

Тоді кількість різальних зерен $\mathrm{m}$ на площі контакту кругу з виробом $F=L_{k} B$ становитиме:

$$
\mathrm{m}=\mathrm{F}_{\mathrm{m}}^{\prime}=\frac{\mathrm{L}_{\mathrm{k}} \cdot \mathrm{B}}{\mathrm{l}_{\Phi}^{2}},
$$

де В - ширина шліфування, мм; $L_{k}$ - довжина дуги контакту, мм (для плоского шліфування $L_{k}=$ $=\mathrm{Dt}) ; \mathrm{I}_{\Phi}-$ фактична відстань між зернами, мм; $F_{m}$ ' - кількість різальних зерен, що припадає на одиницю площі круга; D діаметр шліфування, мм; $\mathrm{t}$ глибина шліфування, мм.

Відстань між зернами $I_{\phi}$ може бути визначена експериментально. Для деяких алмазних зерен, зокрема для алмазу синтетичного (AC) I $I_{\Phi}$ розрахована, експериментально уточнена і використовується при дослідженнях силового поля [15, 17 , 20, 21, 24-26].

3 урахуванням цього було виконано всебічні дослідження. Значення питомих (віднесених до 10 мм ширини кругу) тангенціальної та нормальної складових зусиль різання наведено у табл. 1-3.

Аналіз результатів для обох видів матеріалів показує, що зі збільшенням глибини шліфування нормальна та тангенціальна 
складові зусиль різання закономірно зростають. Це пояснюється збільшенням як навантаження, що припадає на одиничне різальне зерно, так і кількості зерен у зоні контакту шліфувального кругу з виробом.

Також необхідно звернути увагу на досить важливий результат, отриманий при дослідженні тонкого алмазного шліфування широкої гами високолегованих композиційних сплавів: за досить значній зміні режимів різання (наприклад, глибини шліфування $\mathrm{t}_{л}$ у 10 разів - для цілого кола тестування) співвідношення складових сил різання $\mathrm{P}_{\mathrm{y}} / \mathrm{P}_{\mathrm{z}}$ залишається стабільним i незалежно від марки композиту перебуває у межах 1,22-1,82 (для нікелю ХН55ВМТКЮ) та 1,21-1,55 (для сплаву ЭП975), тобто зміни цього показника не перевищують розбіжностей у 12-25 \%. Це свідчить про стабільність безпосередньо процесів різання при застосуванні алмазних інструментів, і саме в цьому полягають переваги тонкого алмазного шліфування порівняно з абразивною обробкою $[8,15,18-21,23,24]$.

Крім того, збільшення у складі композитів таких легуючих елементів як вольфрам, молібден та ванадій, яке, відповідно, призводить до суттєвих змін у механічних характеристиках оброблюваних матеріалів з одночасним погіршенням оброблюємості їх різання, не викликає значних змін у співвідношенні складових сил шліфування $\mathrm{P}_{\mathrm{y}} / \mathrm{P}_{\mathrm{z}}$.

Скоріше за все, це явище може бути пояснено більш високою здатністю до різання алмазних зерен шліфувального кругу і відповідними перевагами алмазного шліфування високолегованих важкооброблюваних композитів на основі відходів нікелевих сплавів порівняно 3 тонким абразивним шліфуванням кругами 3 найгострішими абразивними зернами карбіду кремнію зеленого [8, 15, 23-27].

Таблиця 1

Питомі сили різання при плоскому алмазному шліфуванні композиту ХН55ВМТКЮ + $5 \% \mathrm{CaF}_{2}$

\begin{tabular}{|c|c|c|c|c|c|c|}
\hline \multirow{2}{*}{$\begin{array}{c}\text { Глибина } \\
\text { шліфування по } \\
\text { лімбу верстату }\end{array}$} & \multicolumn{5}{|c|}{ Характеристика кругу } \\
\cline { 2 - 7 } $\mathrm{t}_{\text {л, мм }}$ & \multicolumn{5}{|c|}{ АСМ14Бр1 100 \% } & \multicolumn{3}{|c|}{ ACM14M1 100 \% } \\
\cline { 2 - 7 } & $\mathrm{P}_{\mathrm{z}}, \mathrm{H} / \mathrm{cm}$ & $\mathrm{P}_{\mathrm{y}}, \mathrm{H} / \mathrm{cm}$ & $\mathrm{P}_{\mathrm{y}} / \mathrm{P}_{\mathrm{z}}$ & $\mathrm{P}_{\mathrm{z}}, \mathrm{H} / \mathrm{cm}$ & $\mathrm{P}_{\mathrm{y}}, \mathrm{H} / \mathrm{cm}$ & $\mathrm{P}_{\mathrm{y}} / \mathrm{P}_{\mathrm{z}}$ \\
\hline 0,005 & 18,5 & 22,6 & 1,22 & 21,5 & 30,8 & 1,46 \\
\hline 0,01 & 23 & 35,9 & 1,56 & 27,1 & 41,5 & 1,53 \\
\hline 0,02 & 44,9 & 77 & 1,71 & 57,4 & 76,7 & 1,34 \\
\hline 0,05 & 136,3 & 249 & 1,82 & 159 & 225 & 1,41 \\
\hline
\end{tabular}

Примітка: Верстат - FF-350 «Abawerk» (ФРН); режими шліфування: швидкість кругу - 25 м/с; поздовжня подача - 0,1 мм/подв. хід; обробка без охолодження. 
Таблиця 2

Питомі сили різання при плоскому алмазному шліфуванні сплаву на основі нікелю ЭП975 + $5 \% \mathrm{CaF}_{2}$

\begin{tabular}{|c|c|c|c|c|c|c|}
\hline \multirow{2}{*}{$\begin{array}{c}\text { Глибина } \\
\text { шліфування по } \\
\text { лімбу верстату }\end{array}$} & \multicolumn{5}{|c|}{ Характеристика кругу } \\
\cline { 2 - 7 } $\mathrm{t}_{\text {л, мм }}$ & \multicolumn{5}{|c|}{ АСМ14Бр1 100\% \% } & \multicolumn{3}{|c|}{ АСM14M1 100 \% } \\
\cline { 2 - 7 } & $\mathrm{P}_{\mathrm{z}}, \mathrm{H} / \mathrm{cm}$ & $\mathrm{P}_{\mathrm{y}}, \mathrm{H} / \mathrm{cm}$ & $\mathrm{P}_{\mathrm{y}} / \mathrm{P}_{\mathrm{z}}$ & $\mathrm{P}_{\mathrm{z}}, \mathrm{H} / \mathrm{cm}$ & $\mathrm{P}_{\mathrm{y}}, \mathrm{H} / \mathrm{cm}$ & $\mathrm{P}_{\mathrm{y}} / \mathrm{P}_{\mathrm{z}}$ \\
\hline 0,005 & 16,5 & 20,1 & 1,21 & 18,7 & 20 & 1,06 \\
\hline 0,01 & 24,1 & 34,7 & 1,44 & 26,4 & 40,1 & 1,52 \\
\hline 0,02 & 43,3 & 61 & 1,41 & 60,2 & 62,1 & 1,03 \\
\hline 0,05 & 44,2 & 68,7 & 1,55 & 140 & 149,3 & 1,06 \\
\hline
\end{tabular}

Примітка: Верстат - FF-350 «Abawerk» (ФРН); режими шліфування: швидкість кругу - 25 м/с; поздовжня подача - 0,1 мм/подв. хід; обробка без охолодження.

Вищезазначені закономірності зберігаються для алмазних кругів на різних зв'язках (еластична бакелітно-гумова Бр1 або жорстка металева М1). Це свідчить про об'єктивну єдність отриманих залежностей i, крім того, повністю співпадає із загальними положеннями теорії шліфування [8, 15-22].

При алмазному шліфуванні, використання дрібнозернистих кругів на гліфталевій зв'язці також знижує величини тангенціальної та нормальної складових сили різання (табл. 1-5). Це пояснюється більшою пружністю гліфталевої зв'язки порівняно з керамічною, а також більшою гостротою алмазних зерен

Таблиця 3

Питомі сили різання при плоскому алмазному шліфуванні композиту ХН50ВТФКЮ + $5 \% \mathrm{CaF}_{2}$

\begin{tabular}{|c|c|c|c|c|c|c|}
\hline \multirow{2}{*}{$\begin{array}{c}\text { Глибина } \\
\text { шліфування по } \\
\text { лімбу верстату } \\
\mathrm{t}_{л}, \text { мм }\end{array}$} & \multicolumn{5}{|c|}{ Характеристика кругу } \\
\cline { 2 - 7 } & \multicolumn{5}{|c|}{ АСМ14Бр1 100\% \% } & \multicolumn{3}{|c|}{ ACM14M1 100 \% } \\
\cline { 2 - 7 } & $\mathrm{P}_{\mathrm{z}}, \mathrm{H} / \mathrm{cm}$ & $\mathrm{P}_{\mathrm{y}}, \mathrm{H} / \mathrm{cm}$ & $\mathrm{P}_{\mathrm{y}} / \mathrm{P}_{\mathrm{z}}$ & $\mathrm{P}_{\mathrm{z}}, \mathrm{H} / \mathrm{cm}$ & $\mathrm{P}_{\mathrm{y}}, \mathrm{H} / \mathrm{cm}$ & $\mathrm{P}_{\mathrm{y}} / \mathrm{P}_{\mathrm{z}}$ \\
\hline 0,005 & 16,5 & 18,4 & 1,12 & 22 & 27,3 & 1,24 \\
\hline 0,01 & 22,1 & 35,7 & 1,61 & 28,1 & 38,1 & 1,35 \\
\hline 0,02 & 41,8 & 71,5 & 1,71 & 57,8 & 71,2 & 1,23 \\
\hline 0,05 & 44,3 & 73,1 & 1,65 & 151,1 & 190,7 & 1,26 \\
\hline
\end{tabular}

Примітка: Верстат - FF-350 «Abawerk» (ФРН); режими шліфування: швидкість кругу -25 м/с; поздовжня подача $-0,1$ мм/подв. хід; обробка без охолодження. 
(мінімальний радіус заокруглення $\rho$ при вершині зерна, мінімальний кут різання $\gamma$ зерна) [15, 19-22].

Для розрахунку навантаження на окреме зерно було встановлено, що в процесі стружкоутворення у середньому бере участь 0,1 від всіх зерен, які знаходяться на переферії кругу, тобто:

$$
m=\frac{0,1 \cdot L_{k} \cdot B}{l_{\phi}^{2}}
$$

3 експериментальних даних (табл. 4, 5) зрозуміло, що при тонкому алмазному шліфуванні навантаження, що припадає на одне абразивне зерно, дуже інтенсивно зростає до глибини 0,012 мм. При подальшому збільшенні глибини шліфування величина розрахункового навантаження незначна. Тому подальше збільшення сил різання пов'язане, в основному, тільки зі збільшенням кількості різальних алмазних зерен у зоні контакту шліфувального кругу з виробом.

При використанні еластичних зв'язок, наприклад, гліфталевих, навантаження на одне зерно менше залежить від глибини різання.

При шліфуванні дрібнозернистими кругами показники $\mathrm{P}_{\mathrm{z}}$

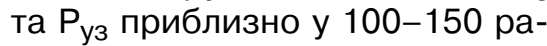
зів менші, ніж при шліфуванні крупнозернистими кругами (табл. 5). Таким значним зменшенням нормальної складової зусилля різання одиничним зерном і пояснюється, в основному, зниження ступеню зміцнення поверхневого шару і умов покращення формування мінімальної шорсткості поверхонь оброблення деталей тертя з нових композитних матеріалів на основі нікелю [15, 23-27] при використанні дрібнозернистих алмазних інструментів.

\section{Висновки}

Узагальнюючи комплекс виконаних досліджень, необхідно зробити такі висновки:

Таблиця 4

Розрахункове навантаження на окреме різальне зерно кругу при алмазному шліфуванні зразків з композиційного сплаву ХН55ВМТКЮ + $5 \% \mathrm{CaF}_{2}$

\begin{tabular}{|c|c|c|c|c|c|c|c|}
\hline \multirow{3}{*}{$\begin{array}{c}\text { Глибина } \\
\text { шліфування } \\
\text { по лімбу } \\
{\text { верстату } t_{л}}_{\text {мм }}\end{array}$} & \multirow{3}{*}{$\begin{array}{c}\text { Довжина } \\
\text { дуги } \\
\text { контакту } \\
L_{k}, \text { мм }\end{array}$} & \multicolumn{6}{|c|}{ Характеристика кругу } \\
\hline & & \multicolumn{3}{|c|}{ АCM14Бр1 $100 \%$} & \multicolumn{3}{|c|}{ ACM14M1 $100 \%$} \\
\hline & & $\mathrm{m}$ & $\mathrm{P}_{\mathrm{z} 3}, \mathrm{H}$ & $\mathrm{P}_{\mathrm{y} 3}, \mathrm{H}$ & $\mathrm{m}$ & $\mathrm{P}_{\mathrm{z} 3}, \mathrm{H}$ & $\mathrm{P}_{\mathrm{y3}}, \mathrm{H}$ \\
\hline 0,005 & 0,80 & 455 & 0,025 & 0,051 & 467 & 0,087 & 0,096 \\
\hline 0,01 & 1,1 & 650 & 0,029 & 0,070 & 573 & 0,185 & 0,112 \\
\hline 0,02 & 1,6 & 890 & 0,052 & 0,086 & 645 & 0,243 & 0,255 \\
\hline 0,05 & 2,7 & 1420 & 0,080 & 0,125 & 955 & 0,356 & 0,387 \\
\hline
\end{tabular}

Примітка: Верстат - FF-350 «Abawerk» (ФРН); режими шліфування: швидкість кругу - 22 м/с; поздовжня подача - 0,1 мм/подв. хід; В - 10 мм; охолодження - 3 \% розчин содової емульсії. 
1. 3 точки зору формування поглядів на процеси утворення умов забезпечення якісних показників поверхонь оброблення деталей тертя високошвидкісних друкарських машин, вперше виконано дослідження силових параметрів поля при тонкому алмазному шліфуванні деталей тертя $з$ нових композиційних сплавів, синтезованих з утилізованих відходів нікелевих сплавів.

2. Задля забезпечення високих вимог до якості виробів 3 нових композитних матеріалів на основі нікелю необхідно враховувати, що найкращі показники (з точки зору дії силових факторів процесу тонкої обробки, зокрема складових сил різання $\mathrm{P}_{\mathrm{z}}, \mathrm{P}_{\mathrm{y}}, \mathrm{P}_{\mathrm{x}}$ ) гарантують застосування інструментів на основі синтетичних алмазів (АC) на бакелітно-гумовій зв'язці (Бр1), які мають зернистість 14-20 мкм.

3. Дослідження показали, що режими різання суттєво вплива- ють на параметри якості поверхонь алмазного оброблення. 3 практичною метою, задля отримання стабільних та високих результатів щодо параметрів якості поверхонь, необхідно забезпечувати такі режими різання: шліфувальний круг АСМ14Бр1 100 \%; швидкість кругу -25 м/с; поздовжня подача - 0,1 мм/подв. хід; ширина шліфування (В) - 10 мм; охолодження - 3 \% розчин содової емульсії.

4. Подальші дослідження процесів тонкого алмазного шліфування нових високолегованих композитних матеріалів доцільно виконувати для вивчення значень миттєвих контактних температур шліфування в зоні різання. У поєднанні з результатами силового поля всебічне вивчення температурного поля на ріжучій кромці алмазного зерна при тонкому шліфуванні дозволить отримати об'єктивні

Таблиця 5

Розрахункове навантаження на окреме різальне зерно кругу при алмазному шліфуванні зразків з композиційного сплаву ЭП $975+5 \% \mathrm{CaF}_{2}$

\begin{tabular}{|c|c|c|c|c|c|c|c|}
\hline \multirow{4}{*}{$\begin{array}{c}\text { Глибина } \\
\text { шліфування } \\
\text { по лімбу } \\
\text { верстату } \mathrm{t}_{л}, \\
\text { мм }\end{array}$} & \multirow{4}{*}{$\begin{array}{c}\text { Довжина } \\
\text { дуги } \\
\text { контакту } \\
\text { L }_{k}, \text { мм }\end{array}$} & \multicolumn{6}{|c|}{ Характеристика кругу } \\
\hline & & \multicolumn{3}{|c|}{$400 \times 32 \times 16 \mathrm{MM}$} & \multicolumn{3}{|c|}{$200 \times 32 \times 16 \mathrm{MM}$} \\
\hline & & \multicolumn{3}{|c|}{ ACM14Бp1 $100 \%$} & \multicolumn{3}{|c|}{ ACM14M1 $100 \%$} \\
\hline & & $\mathrm{m}$ & $\mathrm{P}_{\mathrm{z} 3}, \mathrm{H}$ & $\mathrm{P}_{\mathrm{y} 3}, \mathrm{H}$ & $\mathrm{m}$ & $\mathrm{P}_{\mathrm{z} 3}, \mathrm{H}$ & $\mathrm{P}_{\mathrm{y} 3}, \mathrm{H}$ \\
\hline 0,005 & 0,80 & 15 & 2,1 & 4,1 & 455 & 0,015 & 0,027 \\
\hline 0,01 & 1,1 & 20 & 2,4 & 4,7 & 650 & 0,021 & 0,032 \\
\hline 0,02 & 1,6 & 30 & 2,7 & 5,5 & 890 & 0,029 & 0,041 \\
\hline 0,05 & 2,7 & 45 & 3,1 & 7,1 & 1420 & 0,036 & 0,058 \\
\hline
\end{tabular}

Примітка: Верстат - FF-350 «Abawerk» (ФРН); режими шліфування: швидкість кругу - 25 м/с; поздовжня подача $-0,1$ мм/подв. хід; В -10 мм; охолодження - 3 \% розчин содової емульсії. 
параметри якості поверхонь оброблення i, перш за все, таких важливих факторів як глибина та ступінь наклепу, глибина його залягання, рівень залишкових напружень та їх знак (розтягування чи стискування).
Це дозволить призначати такі режими тонкого шліфування, які забезпечать отримання необхідних параметрів зносостійкості та ремонтоздатності при їх експлуатації в умовах жорстких навантажень.

\section{Список використаної літератури}

1. Костецкий Б. И. Надежность и долговечность машин / Б. И. Костецкий, И. Г. Носовский, Л. И. Бершадский, А. К. Караулов. - К. : Техніка, 1975. -408 с.

2. Костецкий Б. И. Основные вопросы теории трения и изнашивания деталей машин / Б. И. Костецкий. - М. : Машгиз, 1955. - 52 с.

3. Костецкий Б. И. Поверхностная прочность материалов при трении / Б. И. Костецкий, И. Г. Носовский, А. К. Караулов [и др.]. - К. : Наукова думка, 1982. - $126 \mathrm{c.}$

4. Крагельский И. В. Трение и износ / И. В. Крагельский. - М. : Машиностроение, 1968. - 478 с.

5. Крагельский И. В. Основы расчетов на трение и износ / И. В. Крагельский, М. Н. Добычин, В. С. Комбалов. - М. : Машиностроение, 1977. $526 \mathrm{c}$.

6. Рыжов Э. В. Технологические методы повышения износостойкости деталей машин / Э. В. Рыжов. - К. : Наукова думка, 1984. - 340 с.

7. Рыжов Э. В. Контактная жесткость деталей машин : монография / Э. В. Рыжов. - К. : Наукова думка, 1987. - 320 с.

8. Киричок П. О. Фінішне оброблення зносостійких деталей друкарських машин [Текст] : навч. посіб. / П. О. Киричок, Т. А. Роїк, А. П. Гавриш та ін. К. : НТУУ «КП।», 2014. - 514 c.

9. Косторнов А. Г. Триботехническое материаловедение : монография / А. Г. Косторнов. - Луганск : изд. «Ноули», 2012. - 701 с.

10. Порошковая металлургия. Материалы, технология, свойства, области применения : справочник / И. М. Федорченко, И. Н. Францевич, И. Д. Радомысельский [и др.]. - К. : Наукова думка, 1985. - 624 с.

11. Производство порошковых изделий / Г. А. Лебенсон. - 2-е изд., переработ. и дополн. - М. : Металлургия, 1990. - 240 с.

12. Федорченко И. М. Композиционные спеченные антифрикционные материалы / И. М. Федорченко, Л. И. Пугина. - К. : Наук. думка, 1980. $404 \mathrm{c}$.

13. Роїк Т. А. Композиційні підшипникові матеріали для підвищених умов експлуатації : монографія / Т. А. Роїк, П. О. Киричок, А. П. Гавриш. - К. : НТУУ «КПІ», 2007. - 404 с.

14. Роїк Т. А. Новітні композиційні матеріали деталей тертя поліграфічних машин : монографія / Т. А. Роїк, А. П. Гавриш, П. О. Киричок та ін. - К. : НТУУ «КПІ», 2014. - 427 с.

15. Технологія поліграфічного машинобудування [Текст] : навч. посіб. / П. О. Киричок, Т. А. Роїк, А. В. Шевчук та ін. - К. : НТУУ «КПІ», 2014. $508 \mathrm{c}$. 
16. Маслов Е. Н. Теория шлифования материалов / Е. Н. Маслов. - М. Машиностроение, 1979. - 320 с.

17. Мазур М. П. Основи теорії різання матеріалів : підручник / М. П. Мазур, Ю. М. Внуков, В. Л. Доброскок, В. О. Залога, Ю. К. Новоселов, Ф. Я. Якубов, під заг. ред. М. П. Мазура. - Львів : Новий світ, 2010. - 423 с.

18. Ящерицын П. И. Прогрессивная технология финишной обработки деталей / П. И. Ящерицын. - Минск : Беларусь, 1989. - 312 с.

19. Инструменты из сверхтвердых материалов (под. ред. акад. НАН Украины Н. В. Новикова, д-ра техн. наук С. А. Клименко. 2-е изд., перераб. и доп.). - М. : Машиностроение, 2014. - 608 с.

20. Лавриненко В. І. Надтверді абразивні матеріали в механообробці : енциклопедичний довідник / під заг. ред. акад. НАН України М. В. Новікова. - К. : вид-во ІНМ НАН України, 2013. - 456 с.

21. Сверхтвердые материалы. Получение и применение : монография : в 6 т. / под общ. ред. Н. В. Новикова. - К. : ИСМ им. В. Н. Бакуля НАНУ, 2007. $-6 \mathrm{~T}$.

22. Эльбор в машиностроении / под ред. В. С. Лысанова. - М. : Машиностроение, 1978. - 280 с.

23. Гавриш А. П. Алмазно-абразивна обробка магнітних матеріалів : монографія / А. П. Гавриш, П. П. Мельничук. - Житомир : ЖДТУ, 2003. $652 \mathrm{c}$.

24. Гавриш А. П. Шлифование и доводка магнитных материалов / А. П. Гавриш. - Л. : Машиностроение, 1985. - 118 с.

25. Роик Т. А. Обеспечение качества поверхностей деталей из магнитомягких сплавов прецезионной доводкой : монография / Т. А. Роик, П. А. Киричок, А. П. Гавриш, М. Г. Аскеров, Ю. Ю. Вицюк. - К. : НТУУ «КПИ», 2013. -233 c.

26. Гавриш А. П. Вплив фізико-механічних властивостей абразивних матеріалів для поліграфічних машин / А. П. Гавриш, Т. А. Роїк, П. О. Киричок та ін. // Технологія і техніка друкарства. — К. : ВПІ НТУу «КПІ». — 2015. — № 3. - C. 72-84.

27. Оптимізація вибору абразивних матеріалів для шліфування зносостійких деталей з легованих титанових композитів для технологічних комплексів / А. П. Гавриш, Т. А. Роїк, О. І. Лотоцька, В. Г. Олійник // Наукові нотатки «Технологічні комплекси» / Луцький національний технічний університет. - 2014. - № 2. - С. 148-152.

\section{References}

1. Kosteckij, B. I. \& Nosovskij, I. G. \& Bershadskij, L. I. \& Karaulov, A. K. (1975). Nadezhnost' i dolgovechnost' mashin [The reliability and durability of machines]. Kiev: Tekhnika [in Russian].

2. Kosteckij, B. I. (1955). Osnovnye voprosy teorii trenija i iznashivanija detalej mashin [Main questions of the theory of friction and wear of machine parts]. Moscow: Mashgiz [in Russian].

3. Kosteckij, B. I. \& Nosovskij, I. G. \& Karaulov, A. K. (1982). Poverhnostnaja prochnost' materialov pri trenii [Surface strength of materials during friction]. Kiev: Naukova dumka [in Russian]. 
4. Kragel'skij, I. V. (1968). Trenie i iznos [Friction and wear]. Moscow: Mashinostroenie [in Russian].

5. Kragel'skij, I. V. \& Dobychin, M. N. \& Kombalov, V. S. (1977). Osnovy raschetov na trenie $i$ iznos [Fundamentals of calculations on friction and wear]. Moscow: Mashinostroenie [in Russian].

6. Ryzhov, Je. V. (1984). Tehnologicheskie metody povyshenija iznosostojkosti detalej mashin [Technological methods to improve the wear resistance of machine parts]. Kiev: Naukova dumka [in Russian].

7. Ryzhov, Je. V. (1987). Kontaktnaja zhestkost' detalej mashin [Contact rigidity of machine parts]. Kiev: Naukova dumka [in Russian].

8. Kyrychok, P. O. \& Roik, T. A. \& Havrysh, A. P. (2014). Finishne obroblennia znosostiikykh detalei drukarskykh mashyn [Finish treatment of wear parts of printing machines]. Kyiv: NTUU 'KPI' [in Ukrainian].

9. Kostornov, A. G. (2012). Tribotehnicheskoe materialovedenie [Tribological materials science]. Lugansk: izd. 'Nouli' [in Russian].

10. Fedorchenko, I. M. \& Francevich, I. N. \& Radomysel'skij, I. D. (1985). Poroshkovaja metallurgija. Materialy, tehnologija, svojstva, oblasti primenenija [Powder metallurgy. Materials, technology, properties, applications]. Kiev: Naukova dumka [in Russian].

11. Lebenson, G. A. (1990). Proizvodstvo poroshkovyh izdelij [Manufacture of powder products]. Moscow: Metallurgija [in Russian].

12. Fedorchenko, I. M. \& Pugina, L. I. (1980). Kompozicionnye spechennye antifrikcionnye materialy [Composite sintered antifriction materials]. Kiev: Naukova dumka [in Russian].

13. Roik, T. A. \& Kyrychok, P. O. \& Havrysh A. P. (2007). Kompozytsiini pidshypnykovi materialy dlia pidvyshchenykh umov ekspluatatsii [Composite bearing materials for elevated operating conditions]. Kyiv: NTUU 'KPI' [in Ukrainian].

14. Roik, T. A. \& Havrysh, A. P. \& Kyrychok, P. O. (2014). Novitni kompozytsiini materialy detalei tertia polihrafichnykh mashyn [The latest composite materials of the friction pieces for printing machines]. Kyiv: NTUU 'KPI' [in Ukrainian].

15. Kyrychok, P. O. \& Roik, T. A. \& Shevchuk, A. V. (2014). Tekhnolohiia polihrafichnoho mashynobuduvannia [Technology of printing machinery]. Kyiv: NTUU 'KPI' [in Ukrainian].

16. Maslov, E. N. (1979). Teorija shlifovanija materialov [Theory of grinding of materials]. Moscow: Mashinostroenie [in Russian].

17. Mazur, M. P. \& Vnukov, lu. M. \& Dobroskok, V. L. \& Zaloha, V. O. \& Novoselov, lu. K. \& Yakubov, F. la. (2010). Osnovy teorii rizannia materialiv [Fundamentals of the theory of cutting of materials]. Lviv: Novyi svit [in Ukrainian].

18. Jashhericyn, P. I. (1989). Progressivnaja tehnologija finishnoj obrabotki detalej [Progressive technology of finishing details]. Minsk: Belarus' [in Russian].

19. (2014). Instrumenty iz sverhtverdyh materialov [Tools of superhard materials]. Moscow: Mashinostroenie [in Russian].

20. Lavrynenko, V. I. (2013). Nadtverdi abrazyvni materialy v mekhanoobrobtsi [Superhard abrasive materials in the machining treatment]. Kyiv: vyd-vo INM NAN Ukrainy [in Ukrainian].

21. (2007). Sverhtverdye materialy. Poluchenie i primenenie [Superhard materials. Preparation and use]. Kiev: ISM im. V. N. Bakulja NANU [in Russian]. 
22. (1978). Jel'bor v mashinostroenii [Elbor in machine building]. Moscow: Mashinostroenie [in Russian].

23. Havrysh, A. P. \& Melnychuk, P. P. (2003). Almazno-abrazyvna obrobka mahnitnykh materialiv [Diamond-abrasive machining of magnetic materials]. Zhytomyr: ZhDTU [in Ukrainian].

24. Gavrish, A. P. (1985). Shlifovanie i dovodka magnitnyh materialov [Grinding and lapping of magnetic materials]. Leningrad: Mashinostroenie [in Russian].

25. Roik, T. A. \& Kirichok, P. A. \& Gavrish, A. P. \& Askerov, M. G. \& Vicjuk, Ju. Ju. (2013). Obespechenie kachestva poverhnostej detalej iz magnitomjagkih splavov precezionnoj dovodkoj [The quality of surfaces of parts made of magnetic alloys precision lapping]. Kiev: NTUU 'KPI' [in Russian].

26. Havrysh, A. P. \& Roik, T. A. \& Kyrychok, P. O. (2015). Vplyv fizykomekhanichnykh vlastyvostei abrazyvnykh materialiv dlia polihrafichnykh mashyn [The influence of physic-mechanical properties of abrasive materials for printing machines]. Journal of Tekhnolohiia i tekhnika drukarstva - Technology and Technique of Typography, 3, 72-84. Retrieved from http://ttdruk.vpi.kpi.ua/ article/view/54886 [in Ukrainian].

27. Havrysh, A. P. \& Roik, T. A. \& Lototska, O. I. \& Oliinyk, V. H. (2014). Optymizatsiia vyboru abrazyvnykh materialiv dlia shlifuvannia znosostiikykh detalei z lehovanykh tytanovykh kompozytiv dlia tekhnolohichnykh kompleksiv [Selection of abrasive materials for grinding wear-resistant parts made of titanium alloy composites for technological complexes]. Journal of Naukovi notatky 'Tekhnolohichni kompleksy' - Research notes 'Technological complexes', 2, 148-152 [in Ukrainian].

В статье представлены результаты исследования влияния на составляющие сил резания при тонком алмазном шлифовании деталей трения, изготовленных из новых композиционных материалов, созданных на базе отходов производства деталей из никелевых сплавов типа ХН55ВМТКЮ, ХН50ВТФКЮ, ЭП975 в электротехнической, радиоэлектронной и аэрокосмической отраслях промышленности Украины, синтезированных для тяжелых условий работы полиграфической техники. Установлены закономерности влияния режимных факторов шлифовки, типа алмаза, зернистости и материала связи алмазного круга на параметры качества поверхностей обработки с учетом механизма формирования составляющих сил резания на режущей кромке алмазного зерна в зоне резки материала.

Определена зависимость шероховатости поверхностей обработки новых высокоскоростных композитных сплавов от режимов процесса алмазной шлифовки (скорости вращения, продольной подачи, скорости вращения

алмазного круга и зернистости алмазных зерен

в инструменте). Разработаны рекомендации по выбору алмазных кругов и режимов резания для промышлен- 
ности, обеспечивающие качество поверхностей трения высокоскоростных подшипников скольжения для печатной техники.

Ключевые слова: новые композитные материалы; силы резания; шлифовальные круги из алмаза; зернистость; тип связки; алмазное шлифование; режимы резания.

In the article we present the research results concerning the influence on the rectangular components of cutting forces during fine diamond grinding of friction pieces of new composite materials based on wastes of nickel alloys production type HN55VMTKJu, HN50VTFKJu, EP975 in the electrotechnical, radio electronic and aerospace industries of Ukraine and which were synthesized for heavy operating conditions of printing machines.

Keywords: new composite materials; cutting forces; grinding diamond discs; granularity; type of bunch; diamond grinding; cutting parameters. 